Med. thorac. 1965;22:69

\title{
Discussion
}

\section{Paper of REID}

R.Reynolds (Dallas) reported that electron microscopy shows two types of goblet cells in the tracheobronchial tree of rats exposed to S02. One type is found in the trachea, the other in the terminal bronchioles. Differences in the morphology of the goblet cells suggest that there may also be differences in the secreted mucous from the two areas.

He also noted the glands from the tracheobronchial tree are mixed in type, containing both mucous and serous type cells. This is similar to the mixture of cells seen in the submaxillary and sublingual salivary glands.

L. Reid (London) feels that many chronic bronchitics have a phase of hyper-secretion before the onset of infection. 